\title{
Photobiomodulation enhances facial nerve regeneration via activation of PI3K/Akt signaling pathway-mediated antioxidant response
}

\author{
Bohan $\mathrm{Li}^{1} \cdot \mathrm{Xiao} \mathrm{Wang}^{1}$ \\ Received: 16 November 2020 / Accepted: 16 May 2021 / Published online: 24 July 2021 \\ (c) The Author(s) 2021
}

\begin{abstract}
Facial nerve dysfunction is a common clinical condition that leads to disfigurement and emotional distress in the affected individuals. This study aimed to evaluate whether photobiomodulation can enhance regeneration of crushed facial nerves and attempt to investigate the possible underlying mechanism of neuroprotective function and therapeutic target. Various parameters of photobiomodulation were assigned to the facial nerves and Schwann cells (SCs) separately during crushed injury in rats. Axonal regeneration, functional outcomes, and SC apoptosis, proliferation, and underlying mechanisms of action were evaluated by morphological, histopathological, and functional assessments, flow cytometry, western blotting, real-time PCR, and IncuCyte. The results showed that photobiomodulation improved axonal regeneration and functional recovery, and also promoted proliferation, and inhibited apoptosis of SCs, both of these were considered as the most effective parameters in $250 \mathrm{~mW}$ group. In addition, the neuroprotective effects of photobiomodulation $(500 \mathrm{~mW})$ were likely associated with oxidative stress-induced SC apoptosis via activation of the PI3K/Akt signaling pathway. Our results revealed that photobiomodulation significantly promoted axonal regeneration, functional recovery, and regeneration of the facial nucleus, and its mechanism was related to the up-regulation of the PI3K/Akt signaling pathway. These findings provide clear experimental evidence of photobiomodulation as an alternative therapeutic strategy for peripheral nerve damage.
\end{abstract}

Keywords Photobiomodulation $\cdot$ Facial nerve regeneration $\cdot$ PI3K/Akt signaling pathway $\cdot$ Antioxidant response $\cdot$ Schwann cells

\section{Background}

Facial nerve injury combined with the loss of facial expression is a health problem that can significantly deteriorate quality of life (Yasui et al. 2016). Such a condition can seriously hinder the verbal communication conveyed by facial expressions that are considered essential to social relationships. For example, a spontaneous and dynamic smile has a great impact on social interactions (Seo et al. 2018; Lee et al. 2017; Li et al. 2012).

Bohan Li

libohan830117@163.com

Xiao Wang

bysywangxiao@163.com

1 Department of Stomatology, Peking University Third Hospital, No. 49 North Garden Road, Haidian District, Beijing 100191, China
Schwann cells (SCs) have an essential role in axon remyelination. SCs form myelin sheath and maintain its integrity in the peripheral nervous system (PNS) (Shibeeb et al. 2014). SCs can be immediately activated and dedifferentiated during PNS injury to repair the cells, which subsequently stimulates the severed axons to promote axon regeneration (Hou et al. 2018; Wang et al. 2018; Mao et al. 2018; Quintes and Brinkmann 2017).

Numerous in vivo and in vitro studies have shown that biostimulation (i.e., laser treatment and electrical stimulation) promotes adhesion, growth, proliferation, and differentiation of various cells, including neural stem cells, SCs, embryonic stem cells, pluripotent stem cells, and mesenchymal stem cells (Shibeeb et al. 2014; Pouriran et al. 2016; Rimington et al. 2018; Cakir et al. 2016). Previous studies have also revealed that SCs continuously promote the increase of neurite growth under photobiomodulation with a variety of parameters, which in turn could modulate the mobility and differentiation of neural cells. In addition, 
functional, histopathological, morphological, and electrophysiological assessment of photobiomodulation proved its beneficial effects on the regeneration of peripheral nerves following an injury (Yazdani et al. 2012).

According to the previous literature, the phosphatidylinositol-3 kinase/protein kinase B (PI3K/Akt) signaling pathway has an important role in reducing the survival, proliferation, axon growth, and myelin sheath of SCs (Huang et al. 2017; Dong et al. 2019). Huang et al. (2017) reported that PI3K/Akt signaling pathway can accelerate and provide resistance to oxidative stress in neurons. Our data revealed that photobiomodulation has a neuroprotective effect in improving angiogenesis and providing resistance to apoptosis. The purpose of this study was to investigate whether photobiomodulation has a neuroprotective role in facilitating axonal regeneration and functional recovery, and to furthermore explore potentially related molecular mechanisms.

\section{Materials and methods}

\section{Animals and crush injury}

Eight-week-old male Sprague-Dawley (SD) rats weighing 200-250 g were purchased from an animal supplier (KeYu Co., China) (SCXK (Jing) 2016-0002). The animal permission number was XYXK (Jing) 2015-0007. The experiments were performed after adaptation in the animal facility for 1 week.
SD rats were maintained in rooms at constant temperature $\left(22{ }^{\circ} \mathrm{C}\right)$ and humidity $(50 \%)$. The protocol for conducting animal experiments was approved by the Committee for Animal Experimentation of the 309 Hospital of PLA, China (CNU IACUC-H-2013-16). Rats were anesthetized via intraperitoneal injection of Zolletil $®$ (a combination of tiletamine and zolazepam in 1:1 ratio, Virbac, Carros, France) and xylazine hydrochloride. A post-auricular incision was made on the left side of each rat. The main trunk of the facial nerve was exposed, passed through the stylomastoid foramen, and fixed before branching of the main trunk. The entire hemifacial movements were identified by electrical stimulation of the main trunk. The $5 \mathrm{~mm}$ length nerve was crushed with hemostatic forceps for $30 \mathrm{~s}$ from its origin to cause a facial nerve crush defect.

\section{Laser treatment protocol}

In this study, we used a diode laser (Daheng New Epoch Technology, China). The protocol was applied transcutaneously to three points along the facial nerve on the skin surface at a wavelength of $980 \mathrm{~nm}$. Laser therapy was applied from the day after surgery till the postoperative period three times per week for 5 consecutive weeks.

All rats were equally and randomly divided into the following five groups: sham group, with natural facial nerves; control group with crushed nerve injury untreated with irradiation; $250 \mathrm{~mW}$ group treated with an output power of $250 \mathrm{~mW}$, power density of $0.89 \mathrm{~W} / \mathrm{cm}^{2}$, and energy density of $26.5 \mathrm{~J} / \mathrm{cm}^{2} ; 500 \mathrm{~mW}$ group treated with an output power of $500 \mathrm{~mW}$, power density of $1.77 \mathrm{~W} / \mathrm{cm}^{2}$, and energy
Fig. 1 Photobiomodulation on facial nerve regeneration. A, crush injury was performed on the facial nerve of rats; $\mathbf{B}$, photobiomodulation was treated at the facial nerve area after crush injury; $\mathbf{C}$ photobiomodulation was treated on SCs; $\mathbf{D}$, diode laser irradiation of SCs with different parameters (control group; output power $250 \mathrm{~mW}$; output power $500 \mathrm{~mW}$; output power $1000 \mathrm{~mW}$ irradiation for $30 \mathrm{~s} / 8 \mathrm{~h}$ for 12 days)
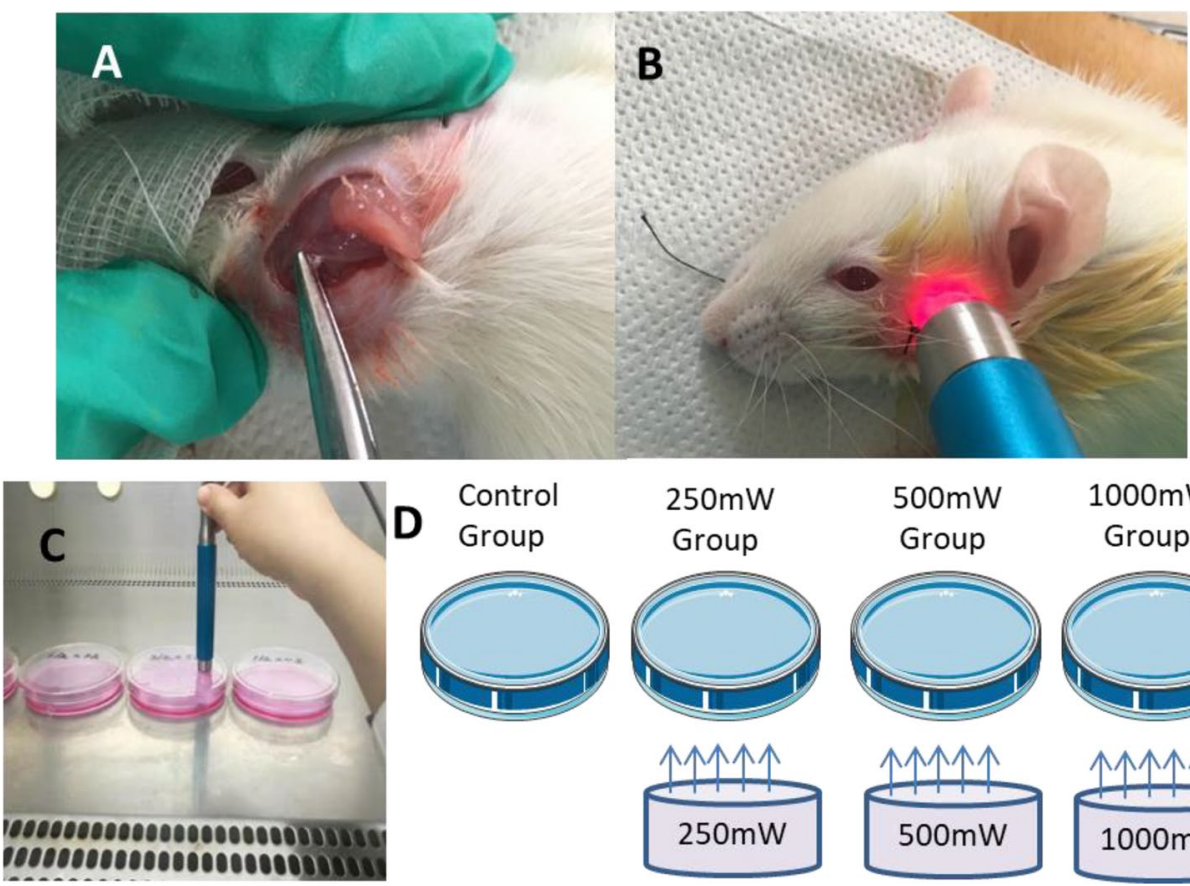

$250 \mathrm{~mW}$

$500 \mathrm{~mW}$

$1000 \mathrm{~mW}$

Group

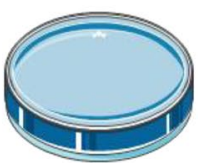

Group

Group
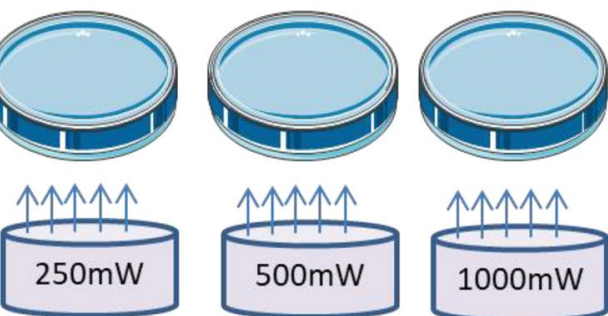
density of $53 \mathrm{~J} / \mathrm{cm}^{2}$; and $1000 \mathrm{~mW}$ Group treated with an output power of $1000 \mathrm{~mW}$, power density of $3.54 \mathrm{~W} / \mathrm{cm}^{2}$, and energy density of $106 \mathrm{~J} / \mathrm{cm}^{2}$ (Fig. 1A, B).

\section{Evaluation of vibrissa movement}

Vibrissa movement was graded based on five points to assess the whisking behavior of the animals: 0 , no whisker movement; 1 , slight whisker movement; 2 , slow movement; 3, rapid movement, but different from that of contralateral normal side; and 4, symmetric movement as compared to the normal side. Evaluation of the vibrissa movement was performed at weeks 4,8 , and 12 . The assay was set in a blinded fashion in order to avoid subjective bias (Table 1) (Chao et al. 2016).

\section{Culture of SCs and parameter of photobiomodulation}

SCs (RSC96 cell lines) were obtained from Shanghai cell bank, Chinese Academy of Sciences. The cells were culture in DMEM-F12 containing 10\% fetal bovine serum (at $37{ }^{\circ} \mathrm{C}$ in a humidified incubator with $10 \% \mathrm{CO}_{2}$ ) followed by incubation for $24 \mathrm{~h}$ to allow cell attachment prior to photobiomodulation. Photobiomodulation with continuous pulse produced by a diode laser was then applied to rats. A total of four separated groups, including control group - with no laser irradiation; $250 \mathrm{~mW}$ group - output power of $250 \mathrm{~mW}$, power density of $0.89 \mathrm{~W} / \mathrm{cm}^{2}$, energy density of $26.5 \mathrm{~J} / \mathrm{cm}^{2}$, and irradiation for $30 \mathrm{~s} / 8 \mathrm{~h}$ for 12 days; $500 \mathrm{~mW}$ group—output power of $500 \mathrm{~mW}$, power density of $1.77 \mathrm{~W} / \mathrm{cm}^{2}$, energy density of $53 \mathrm{~J} / \mathrm{cm}^{2}$, and irradiation for $30 \mathrm{~s} / 8 \mathrm{~h}$ for 12 days; and $1000 \mathrm{~mW}$ groupoutput power of $1000 \mathrm{~mW}$, power density of $3.54 \mathrm{~W} / \mathrm{cm}^{2}$, energy density of $106 \mathrm{~J} / \mathrm{cm}^{2}$, and irradiation for $30 \mathrm{~s} / 8 \mathrm{~h}$ for 12 days, were set up. The large-light-spot handle of the diode laser was perpendicularly placed to each Petri dish, and the light spot on the Petri dish followed an S-shaped track to ensure irradiation of each area (Fig. 1C, D). The medium was then supplemented with $100 \mu \mathrm{m}_{2} \mathrm{O}_{2}$ for

Table 1 Evaluation of vibrissa movement

\begin{tabular}{ll}
\hline $\begin{array}{l}\text { Different } \\
\text { scores }\end{array}$ & Vibrissa movement evaluation \\
\hline 0 & No whisker movement \\
1 & Slight whisker movement \\
2 & Slow movement \\
3 & $\begin{array}{l}\text { Rapid movement, but distinguishable from that of the } \\
\text { contralateral normal side }\end{array}$ \\
4 & Symmetric movement as compared to the normal side \\
\hline
\end{tabular}

another $2 \mathrm{~h}$. To further evaluate the effect of PI3K/Akt activation on oxidative injury, SCs were pretreated with PI3K inhibitor LY294002 $(20 \mu \mathrm{m})$ for $2 \mathrm{~h}$ before undergoing photobiomodulation (Dong et al. 2019; Sang et al. 2018).

\section{Proliferation, migration, and morphology of SCs}

The proliferation of SCs was evaluated by seeding the cells at a density of $8.0 \times 10^{4}$ cells/well into 6 -well plates, which were then cultured by DMEM supplemented with $1 \%$ penicillin/streptomycin and $10 \% \mathrm{FBS}$ at $37{ }^{\circ} \mathrm{C}$ in a humidified atmosphere containing $5 \% \mathrm{CO}_{2}$. The morphology of SCs after photobiomodulation was depicted via immunofluorescence staining technology. Briefly, the samples were fixed with $4 \%$ paraformaldehyde for $24 \mathrm{~h}$ at $4{ }^{\circ} \mathrm{C}$. The mouse anti-S100 (1:500, ABCAM, USA) and anti-neurofilament 200 (1:80; Sigma, USA) antibodies were applied as primary antibodies overnight at $4{ }^{\circ} \mathrm{C}$. Secondary antibodies, including goat anti-rabbit IgG (FITC)/goat anti-mouse IgG (TRITC) (Dako Japan) and DAPI (1:200, Life Technologies), were applied for $1 \mathrm{~h}$ at room temperature. The images were acquired by using a laser confocal microscope (FV10ioil, push around, Tokyo, Japan).

For real-time live-cell analysis of SCs, the cells were seeded into 96-well culture plates at a density of $3 \times 10^{3}$ cells $/ \mathrm{ml}$. Cell viability was measured using an IncuCyte $\mathrm{S} 3$ (Essen BioScience MA, USA) at $6 \mathrm{~h}, 12 \mathrm{~h}, 18 \mathrm{~h}, 24 \mathrm{~h}, 30 \mathrm{~h}$, $36 \mathrm{~h}, 42 \mathrm{~h}, 48 \mathrm{~h}, 54 \mathrm{~h}$, and $60 \mathrm{~h}$ time points during the assay. By counting the total number of cells in each subregion and dividing it by the area of the subregion, an estimate of the local cell density in that subregion was obtained.

\section{Apoptosis analysis by flow cytometry}

SCs after photobiomodulation in the logarithmic phase were inoculated in the culture medium at a density of $2 \times 10^{4}$ cells/ well and cultured at $37{ }^{\circ} \mathrm{C}$ for 3 days. After that, $0.25 \%$ trypsin was digested, centrifuged (1000 r/min, $5 \mathrm{~min}$ ), and maintained in supernatant liquor. The supernatant was then discarded, and the precipitated SCs were gently mixed with $70 \%$ pre-cooled ethanol. After fixing the cells at $4{ }^{\circ} \mathrm{C}$ overnight, the SCs were re-suspended after centrifugation (1000 $\mathrm{r} / \mathrm{min}, 5 \mathrm{~min}$ ). Next, $25 \mathrm{ml}$ propidium iodide (PI) and $20 \mathrm{ml}$ RNase A were added to $1 \mathrm{ml}$ of dyeing buffer solution and then were blended. Each cell sample was mixed with $0.5 \mathrm{ml}$ PI staining solution. The suspended cells were homogenized, incubated at $37^{\circ} \mathrm{C}$ away from light for $30 \mathrm{~min}$, and observed via flow cytometry. Red fluorescence was detected at an excitation wavelength of $488 \mathrm{~nm}$. 


\section{Histomorphometric evaluation}

At the end of the 12-week follow-up period, 6 rats per group were anesthetized. The facial nerve was exposed, and the facial nerve of the crush injury segment was obtained. The samples were immediately immersed in a fixation solution containing $2.5 \%$ glutaraldehyde in phosphate-buffered saline (PBS, pH 7.4) at $4{ }^{\circ} \mathrm{C}$ for $24 \mathrm{~h}$. The distal portion ( $5 \mathrm{~mm}$ distal to the injury) was used for immunofluorescence and histopathology evaluation. The $20-30 \mu \mathrm{m}$ thick cross sections were cut by a freezing microtome. The mouse anti-S100 (1:500, ABCAM, USA) and anti-neurofilament 200 (1:80; Sigma, USA) primary antibodies were applied and incubated overnight at $4{ }^{\circ} \mathrm{C}$. The goat anti-rabbit IgG (FITC) and anti-mouse IgG (TRITC) secondary antibodies (Dako Japan) were applied for $1 \mathrm{~h}$ at room temperature. The images were then acquired under a confocal laser microscope (FV10i-oil, push around, Tokyo, Japan), and were digitally recorded and processed by Image-Pro Plus.

The mean fiber density was calculated by dividing the total number of myelinated nerve fibers within the sampling field by its area $\left(\mathrm{N} / \mathrm{mm}^{2}\right)$. To assess myelin thickness, ultrathin sections were obtained by the same ultra-microtome (Leica, Ultracut) and double-stained with uranyl acetate and lead citrate. The sections were analyzed with a transmission electron microscope (TEM, JSM 1200 IIEX, JEOL, Tokyo, Japan). After imaging of myelin, OPTIMAS Ver. 6.5 (Media Cybernetics, Bethesda, MD) was used to measure myelin thickness.

\section{Retrograde nerve labeling}

Retrograde labeling and counting of back-labeled sensory neurons were performed as previously described (Li et al. 2012). The retrograde labeling of the facial nerve sample with 1,1'-dioctadecyl-3,3'3'-tetramethylindocarbocyanine perchlorate (Dil, C59H97ClN2O4, Molecular Probes; Eugene, OR, USA) was used for measuring nerve regeneration after photobiomodulation. Five days after Dil injection in the facial nerve, rats were rapidly anesthetized using an intraperitoneal injection of chloropent $(3 \mathrm{ml} / \mathrm{kg})$, and transcardially perfused using a $0.9 \%$ saline solution with 1\% heparin (JW Pharmaceutical, Seoul, Korea) followed by $4 \%$ paraformaldehyde (Merck, Darmstadt, Germany) in $0.1 \mathrm{M}$ sodium phosphate buffer (pH7.2). Immediately after fixation, the facial nuclei were extracted and post-fixed with the same fixative at $4{ }^{\circ} \mathrm{C}$ for $24 \mathrm{~h}$. To prevent the occurrence of freezing artifacts during the preparation of frozen tissue sections, the tissues were fixed in $30 \%$ sucrose (Sigma, St, Louis, MO, USA) at $4{ }^{\circ} \mathrm{C}$ for $24 \mathrm{~h}$. The tissue sections were observed using a confocal laser-scanning microscope (CLSM, LSM700, Carl Zeiss, Oberkochen, Germany). The number of Dil back-labeled neurons in each facial nuclei was counted, and the means were then compared among the groups. The labeled neurons at each facial nuclei section were randomly selected, and the soma size of the neuron was measured and averaged with computer software (OPTIMAS Ver. 6.5) according to the technique reported by $\mathrm{Li}$ et al.

\section{Western blot analysis}

Facial nerve protein was extracted, and western blot analysis and quantification were performed as previously described (Sang et al. 2018). All proteins were extracted via Trizol (peqGold TriFast, Peqlab), precipitated from the organic phase using ethanol, and pelleted by centrifugation $\left(12,000 \mathrm{~g}, 10 \mathrm{~min}\right.$, and $\left.4{ }^{\circ} \mathrm{C}\right)$. The protein pellets were washed three times with a combination of $5 \% 0.3 \mathrm{~mol} / \mathrm{l}$ guanidine hydrochloride (Sigma-Aldrich) and 95\% ethanol and once with $100 \%$ ethanol (Merck) and followed by centrifugation $\left(7500 \mathrm{~g}, 5 \mathrm{~min}, 4{ }^{\circ} \mathrm{C}\right)$. The supernatants were discarded and the dry protein pellets were solubilized in analytical grade water with $1 \%$ sodium dodecyl sulfate (SDS, Sigma-Aldrich) in it. The protein was equally separated (up to $3 \mu \mathrm{g} / \mathrm{lane}$ ) on a gel with $12 \%$ SDS-polyacrylamide and blotted onto a nitrocellulose membrane. The membranes were blocked with $5 \%$ skimmed milk in Tris-buffered saline for $120 \mathrm{~min}$, incubated with primary antibodies, and diluted in 5\% bovine serum albumin (Sigma-Aldrich) in TBS-T in a roll mixer at $4{ }^{\circ} \mathrm{C}$ for $12 \mathrm{~h}$. The antibodies included NGF (1:1000), BDNF (1:1000), p-Akt (1:1000), Akt (1:1000), Nrf2 (1:1000), Bcl-2 (1:1000), Bax (1:1000), and GAPDH $(1: 10,000)$. The membrane was washed twice with TBS-T, incubated in $1 \times$ New Blot IR Stripping Buffer (LI-COR Biosciences) on a shaker at room temperature for $5 \mathrm{~min}$, and washed thrice in PBS, and the membranes were then reproved with total antibodies. The ratio of analyzed protein to housekeeping gene $\alpha$-tubulin was analyzed with densitometry by Image Studio Version 5.0.21 (LICOR Biosciences).

\section{Quantification of NGF, p75NTR, and trkA mRNA expression by real-time PCR}

Twelve weeks after surgery, 3 animals per group were anesthetized, and the facial nucleus (FNs) of the left side was obtained. Total RNA was extracted with Trizol reagent (Invitrogen, Carlsbad, CA, USA), and reverse transcribed into cDNA by first-strand synthesis kit (Invitrogen). The amount of cDNA was counted by real-time PCR. The following primers were used to replicate specific cDNA segments: NGF (GenBank Reference Sequence no: XM_227523.3), 
Table 2 Primer sequences

\begin{tabular}{lllll}
\hline Gene & Sequence(5'-3') & $\begin{array}{l}\text { mRNA posi- } \\
\text { tion (start) }\end{array}$ & $\begin{array}{l}\text { mRNA posi- } \\
\text { tion (end) }\end{array}$ & $\begin{array}{l}\text { Product } \\
\text { size } \\
\text { (bp) }\end{array}$ \\
\hline NGF & $\begin{array}{l}\text { Forward: AAG ACC ACA GCC ACG GAC AT } \\
\text { Reverse: CGC CTT GAC AAA GGT GTG AG }\end{array}$ & 722 & 916 & 195 \\
p75 & & 770 & 921 & 152 \\
TrkA & $\begin{array}{l}\text { Forward: TGG CGG ATA TGG TGA CCA CT } \\
\text { Reverse: GCA GCT GTT CCA CCT CTT GA }\end{array}$ & $\begin{array}{l}\text { Forward: AGC CGT GGA ACA GCA TCA CT } \\
\text { Reverse: CGC ATG GTC TCA TTG GTC AG }\end{array}$ & 943 & 1095 \\
GAPDH & $\begin{array}{l}\text { Forward: GCA TCC TGC ACC AAC T } \\
\text { Reverse: GCA GTG ATG GCA TGG ACT GT }\end{array}$ & 802 & 902 & 153 \\
\hline
\end{tabular}

p75NTR (GenBank Reference Sequence no. X05137.1), trkA (GenBank Reference Sequence no. M85214.1), and glyceraldehyde-3-phosphate dehydrogenase (GAPDH) (GenBank Reference Sequence no: NM_017008.3) (Table 2). GAPDH was used as an internal control for normalization. The relative mRNA levels were derived by the cycle threshold $(\triangle \mathrm{Ct})$ method as previously described (Applied Biosystems Manual, Foster City, CA). The PCR reactions were assessed at least twice (Li et al. 2012).

\section{Statistical analysis}

All measurements and histological observations were carried out in a blinded fashion. The measurement data were expressed as means \pm standard deviation. A one-way analysis of variance (ANOVA) was used for comparing multiple groups, followed by Tukey's test. Fisher's exact test was used for comparing mortality among groups. A P-value of $\leq 0.05$ was considered statistically significant. All data were examined using SPSS 21.0 statistical software (SPSS Inc., Chicago, IL, USA).

\section{Results}

\section{Photobiomodulation improves facial nerve regeneration}

Double immunohistochemistry with anti-NF200 and anti$\mathrm{S} 100 \mathrm{~b}$ of injured facial nerves was performed 12 weeks after surgery. Interestingly, S100 positive (green) myelin sheaths surrounded NF200 positive (red) axons were observed in all cross sections. The myelin sheaths were thicker in the $250 \mathrm{~mW}$ and $500 \mathrm{~mW}$ groups than those in the control group. In addition, stronger axonal regeneration and larger myelin sheath coverage were found in $250 \mathrm{~mW}$ and $500 \mathrm{~mW}$ groups than in the crush group (Fig. 2A1-E3). The density of immunopositive areas of both NF200 and S100 in the $250 \mathrm{~mW}$ and $500 \mathrm{~mW}$ groups was greatly increased in the crush group and was similar to the normal nerve tissues
(Fig. 2F) (normal group: 16,001 $\pm 1809 \mathrm{~mm}^{2}$; crush group: $14,000 \pm 2100 \mathrm{~mm}^{2} ; 250 \mathrm{~mW}$ group: $17,530 \pm 2600 \mathrm{~mm}^{2}$; $500 \mathrm{~mW}$ group: $16,331 \pm 1800 \mathrm{~mm}^{2}$; and $1000 \mathrm{~mW}$ group: $14,300 \pm 1600 \mathrm{~mm}^{2}$ ).

TEM was used to evaluate the degree of denervation, revealing a deficit in the myelinated fiber population in the crush group compared to other laser groups (Fig. 2A4-E4). Increased myelinated fibers were observed in both $250 \mathrm{~mW}$ and $500 \mathrm{~mW}$ groups when compared to the crush group (Fig. 2G). Regenerated myelinated fibers in the $500 \mathrm{~mW}$ group showed well-regulation in micro-fascicles, which was similar to that of normal nerve fibers and somewhat greater than those in the crush group. It is widely recognized that axon counting and myelin thickness are crucial for assessing axonal myelination. The myelin thickness was significantly $(\mathrm{P}<0.05)$ higher in both $250 \mathrm{~mW}$ and $500 \mathrm{~mW}$ groups compared to the laser group.

On day 1 of operation, all rats were deprived of their ability to whisk, and later the function of vibrissae movement was gradually recovered. At week 4 after laser therapy, the degree of vibrissa movement was a little higher in the $1000 \mathrm{~mW}$ group than in other groups, but the difference was insignificant. At weeks 8 and 12 after surgery, the average vibrissae movement grade of rats in all laser groups was higher compared to the control group. In particular, the grade of the $500 \mathrm{~mW}$ group was significantly higher compared to the control group at weeks 8 and 12 (Fig. 2H).

\section{Nerve regeneration in the facial nucleus}

After photobiomodulation treatment on rats with crushed injury facial nerve, Dil staining was performed to investigate the retrogradely labeled neurons in the facial nucleus (Fig. 3A-E). The mean number of labeled neurons in the control group and $250 \mathrm{~mW}$ group was significantly greater than that in the crushed injury group (Fig. 3F). The size of soma in the labeled neuron remained the largest in the $250 \mathrm{~mW}$ group when compared to other groups (Fig. 3G) without statistical significance. 

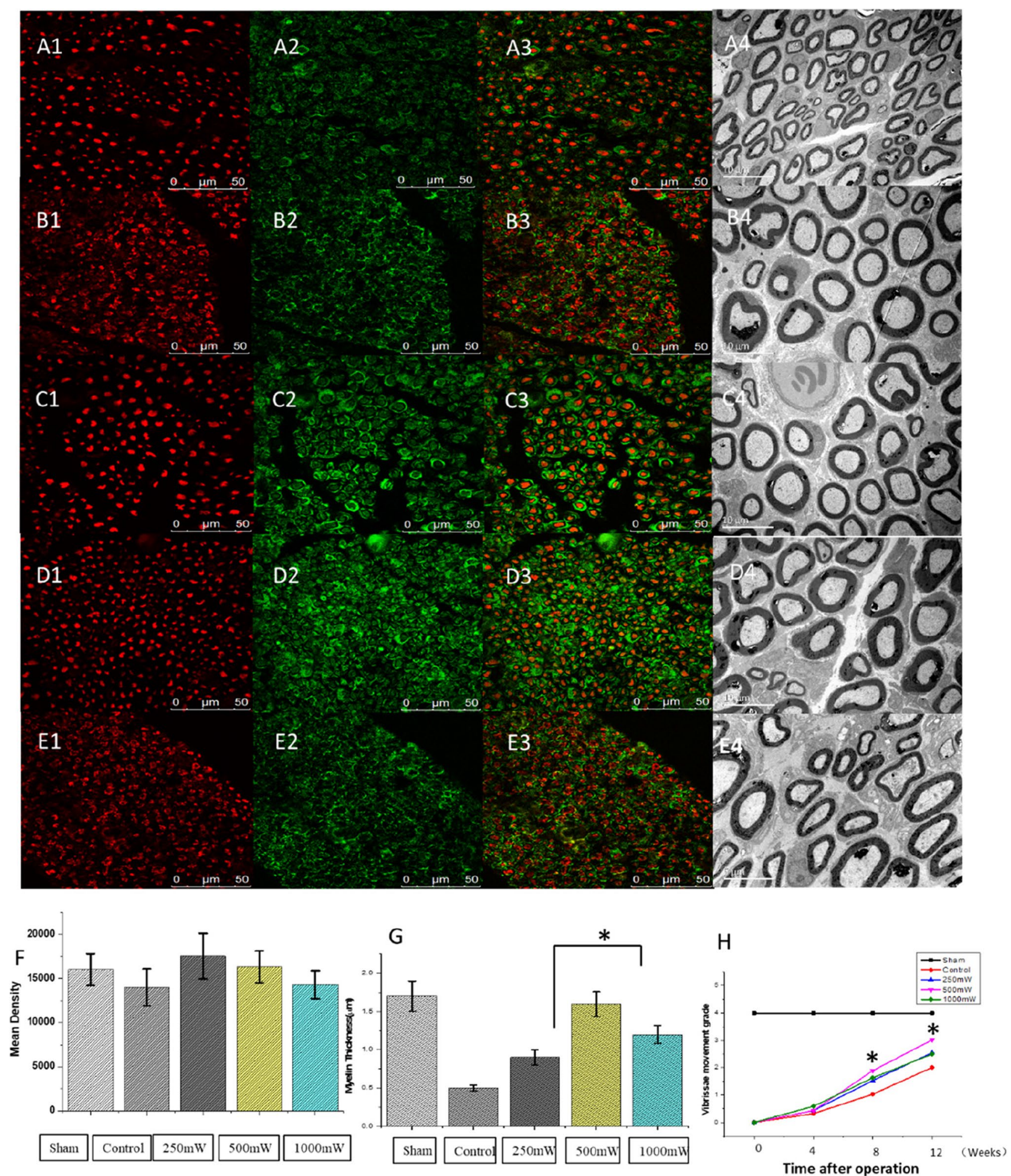

Fig. 2 Photobiomodulation improves facial nerve regeneration. NF-200 (red) and S-100 (green) in cross sections of facial nerves at week 12 after the operation. Sham group (A1-A3), control group (B1-B3), 250mW group (C1-C3), 500mW group (D1-D3), and $1000 \mathrm{~mW}$ group (E1-E3). Scale bar: $50 \mu \mathrm{m}$. Electron microscopic analysis in cross sections of facial nerves at week 12 after operation in groups: A4, sham group; B4, control group; C4, 250mW group; $\mathrm{D} 4,500 \mathrm{~mW}$ group; and $\mathrm{E} 4,1000 \mathrm{~mW}$. The presence of more regener- ated myelin nerve fibers in $250 \mathrm{~mW}$ and $500 \mathrm{~mW}$ groups. F, quantitative analysis of the mean density of fluorescence intensity. $\left({ }^{*} \mathrm{p}<0.05\right)$ $\mathrm{G}$, quantitative analysis of myelin sheath thickness. Scale bar: $10 \mu \mathrm{m}$. $\mathrm{H}$, vibrissa movement grade. The vibrissa movement was assessed at weeks 4,8 , and 12 after treatment with photobiomodulation. The vibrissae movement in the $500 \mathrm{~mW}$ group was faster than in the control groups at weeks 8 and $12(\mathrm{p}<0.05)$ 


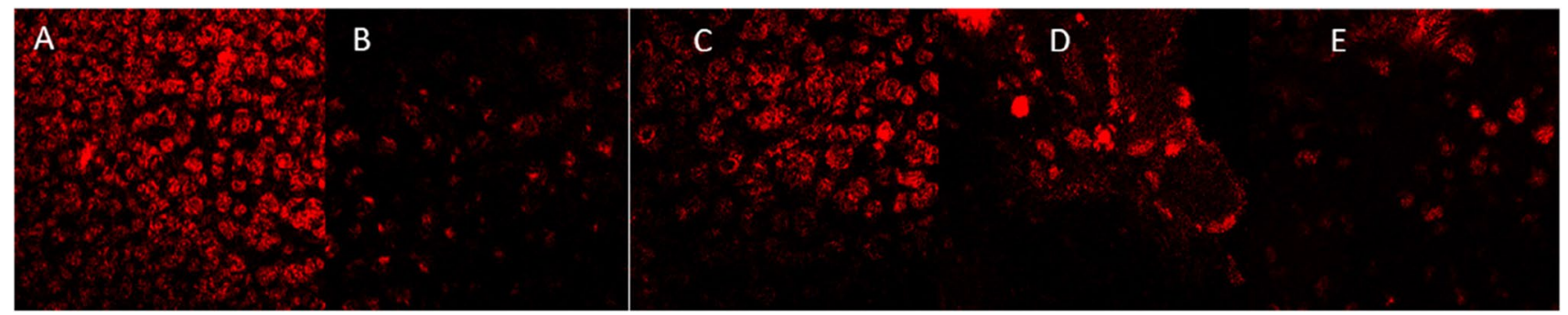

$\mathbf{F}$

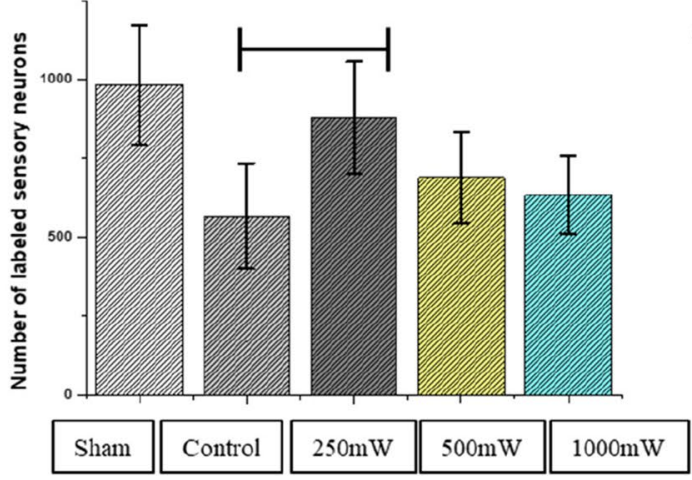

G

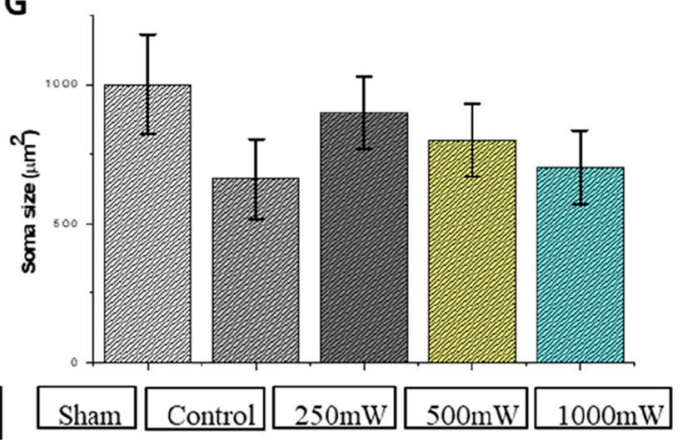

Fig. 3 Retrograde nerve labeling in facial nucleus. Dil staining was performed to investigate labeled neurons in the facial nucleus (sham group (A), control group (B), $250 \mathrm{~mW}$ group $(\mathbf{C}), 500 \mathrm{~mW}$ group (D), and $1000 \mathrm{~mW}$ group $(\mathbf{E})$ ) in retrograde. The $250 \mathrm{~mW}$ group showed

\section{Photobiomodulation increases functional protein secretion and mRNA levels}

The morphological observation under an inverted optical microscope showed that SCs after photobiomodulation in $250 \mathrm{~mW}$ and $500 \mathrm{~mW}$ had healthy growth and adhered to the wall, resembling the spindle-shaped willow leaves, which was similar to that in the control group. Compared with the control group (without laser irradiation), SCs in the $500 \mathrm{~mW}$ group demonstrated the highest cell density under a microscope (Fig. 4A1-D3). The mean fluorescence intensity of $\mathrm{S} 100$ in the $500 \mathrm{~mW}$ group was increased and was the highest when compared to all other groups, and significantly higher than the control group (Fig. 4E).

Western blot analysis performed with photodensitometry is presented in Fig. 4F. Western blot analysis of SCs protein lysate demonstrated the highest level of nerve growth factor (NGF) in $1000 \mathrm{~mW}$ group without any significant difference. Furthermore, the highest level of bone-derived neurotrophic factor (BDNF) in the $250 \mathrm{~mW}$ group was significantly different compared to the control group (Fig. $4 \mathrm{~F})\left({ }^{*} \mathrm{P}<0.05\right)$.

Quantitative RT-PCR of NGF, p75NTR, and trkA expression is shown in Fig. 4I-K, and the results revealed that the levels of all three markers were significantly highest in the $500 \mathrm{~mW}$ group $(* * \mathrm{P}<0.01)$. The mRNA expression levels of TrkA and p75NTR in the $1000 \mathrm{~mW}$ group were also significantly higher compared to the control group $(* \mathrm{P}<0.05)$. improved recovery, and the number of retrograde-labeled neurons $(\mathbf{F})$ and soma size of the facial nucleus $(\mathbf{G})$ were larger compared with the crush injury groups) $(\mathrm{p}<0.05)$

\section{The SCs viability by IncuCyte}

The real-time live-cell viability was analyzed using the Incucyte. To check the effects of photobiomodulation on the cell viability in SCs. SCs were seeded in a 96-well plate. Data were analyzed in three subregions within each IncuCyte S3 image at 6 h, $12 \mathrm{~h}, 18 \mathrm{~h}, 24 \mathrm{~h}, 30 \mathrm{~h}, 36 \mathrm{~h}, 42 \mathrm{~h}, 48 \mathrm{~h}, 54 \mathrm{~h}$, and $60 \mathrm{~h}$ time points during the assay (Fig. 5A1-D4). Figure 5 shows the time evolution of the average cell density, calculated by averaging the six estimates of cell density from each subregion at each time point. The viability of all the SCs in each group gradually increased with the incubation time. The cell viability in the $250 \mathrm{~mW}$ group was higher than in other groups.

\section{Photobiomodulation inhibits apoptosis in vitro}

As shown in Fig. 6, apoptosis of SCs treated with photobiomodulation was analyzed by annexin V and PI staining. The results of flow cytometry analysis showed that the apoptotic rate was significantly decreased in the $250 \mathrm{~mW}$ group $(7.91 \%)$ and in the $500 \mathrm{~mW}$ group $(8.27 \%)$ compared to the control group (14.24\%). However, the apoptotic rate of $1000 \mathrm{~mW}$ group was significantly higher than that of the control group (Fig. 6A-E) ( $p>0.05)$. This suggested that photobiomodulation can inhibit apoptosis of SCs at the parameter of $250 \mathrm{~mW}$ and $500 \mathrm{~mW}$. 

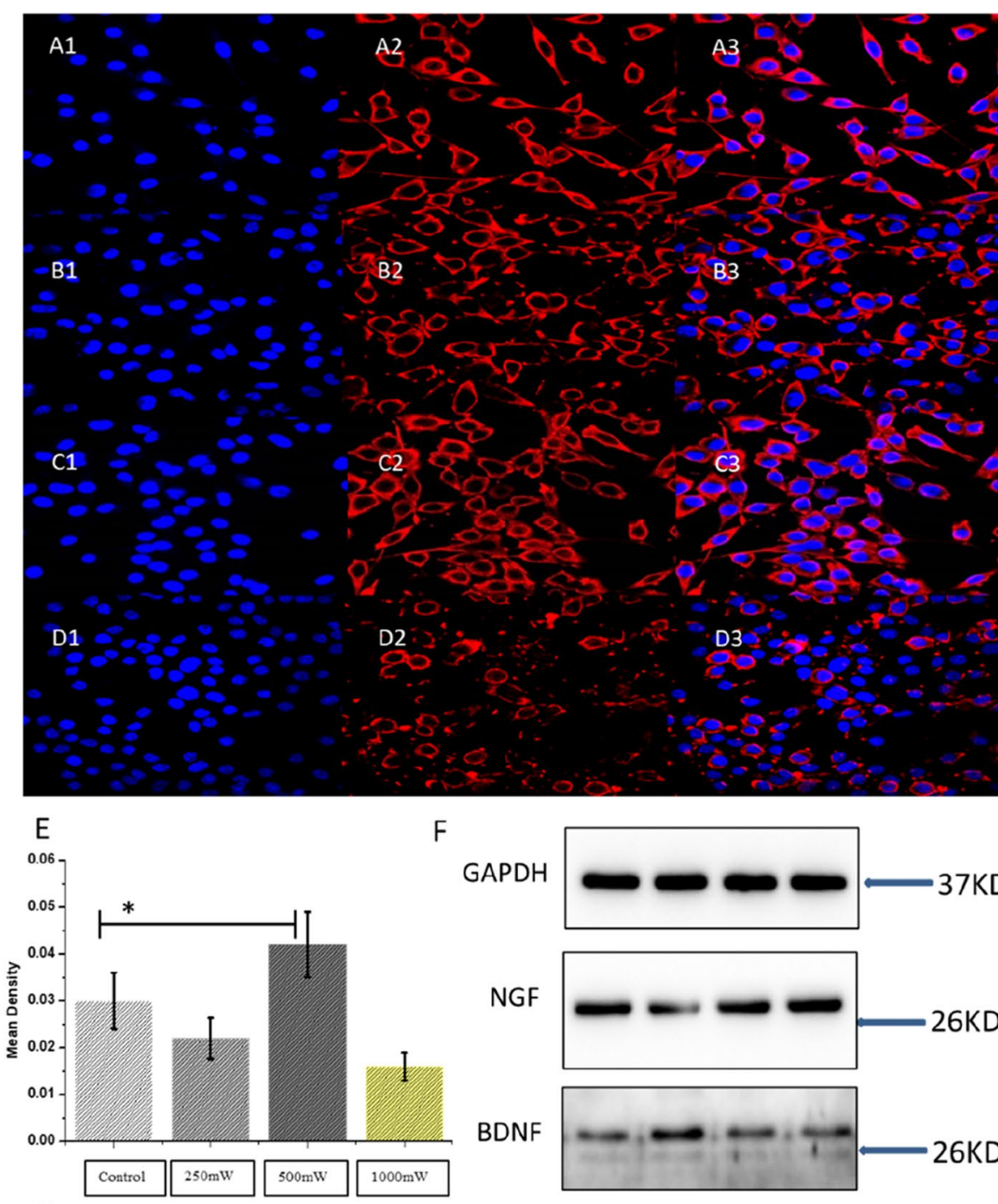

F GAPDH
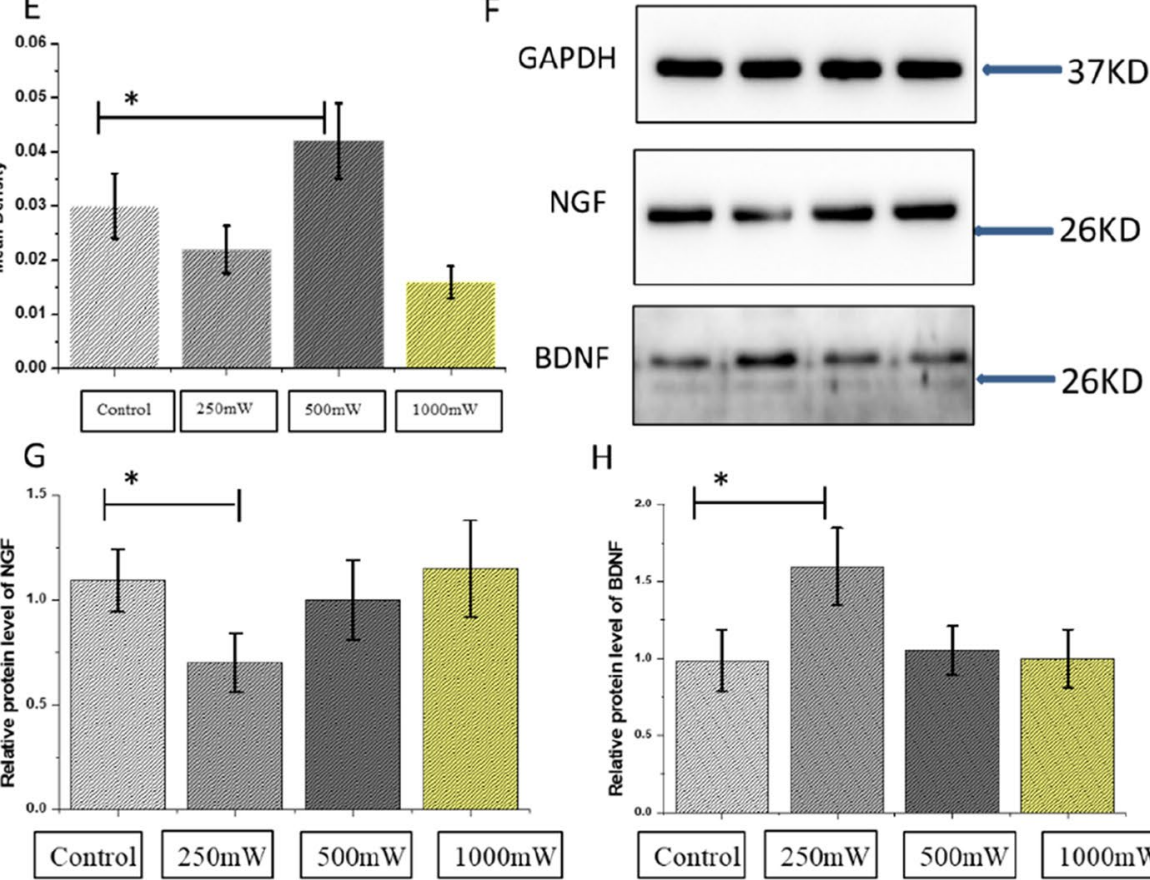

$\mathrm{H}$
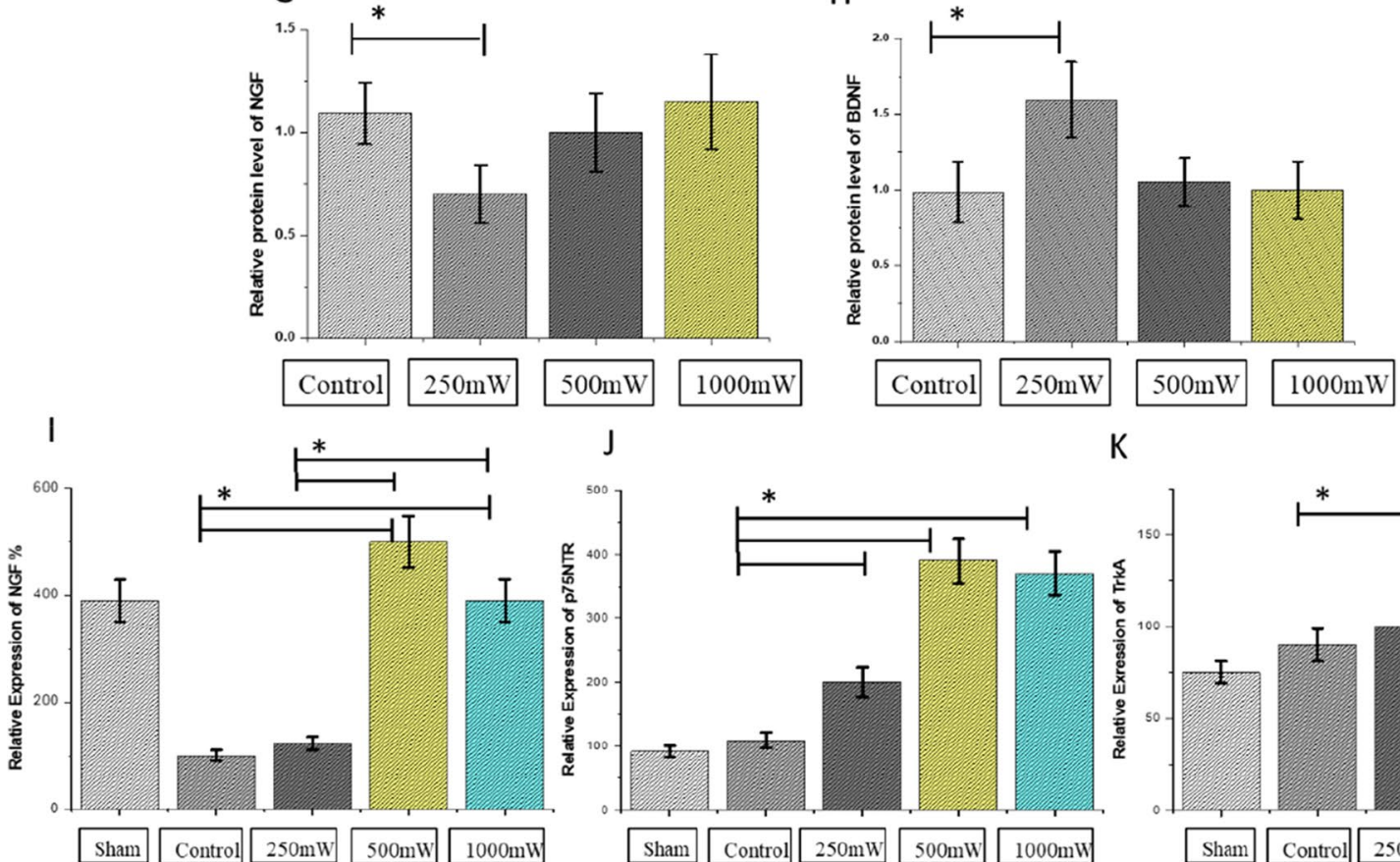

K

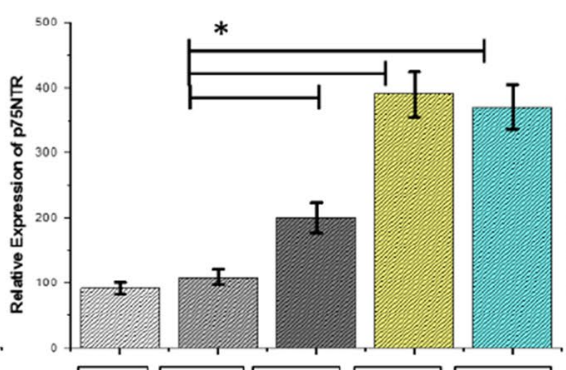

\begin{tabular}{|llll}
\hline Sham & Control $250 \mathrm{~mW}$ & $500 \mathrm{~mW}$ & $1000 \mathrm{~mW}$ \\
\hline
\end{tabular}

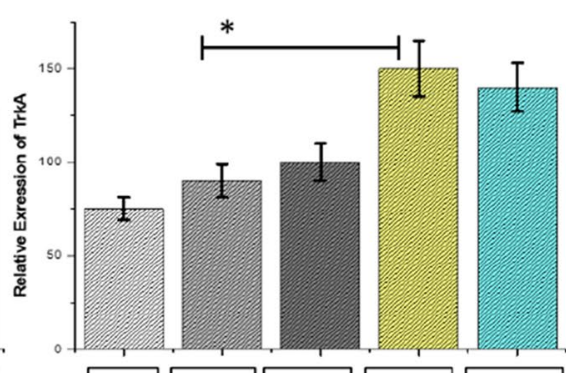

\begin{tabular}{|llll}
\hline Sham & Control $250 \mathrm{~mW}$ & $500 \mathrm{~mW}$ & $1000 \mathrm{~mW}$ \\
\hline
\end{tabular} 
4Fig. 4 Immunofluorescence images of SCs treated with photobiomodulation for 12 days. The S100 marker of SCs was stained in red, and the nuclei were stained by DAPI in blue (A1-D3). Scale bar $=100 \mu \mathrm{m}$. E, quantitative analysis of the mean density of S100 fluorescence intensity (control\&500mW, $* \mathrm{p}<0.05$ ). F, western blotting of protein levels of NGF and BDNF in SCs irradiated by diode level laser (control\&500mW, *p<0.05). G-H, quantification analysis of NGF and BDNF expression. I-K, quantitative real-time polymerase chain reaction (relative expression, \%) of NGF, p75NTR, and TrkA mRNA expression levels in the facial nerve at week 12 after operation $(* * \mathrm{P}<0.01 ; * \mathrm{P}<0.05)$

Western blotting was used for further detection of apoptosis of SCs caused by $\mathrm{H}_{2} \mathrm{O}_{2}$. The results showed downregulation of $\mathrm{Bax}$ and up-regulation of Bal-2 levels in photobiomodulation-treated SCs when compared with $\mathrm{H}_{2} \mathrm{O}_{2}$-treated SCs. The results suggested that photobiomodulation has anti-oxidative effects in reducing apoptosis (Fig. 6F-H). Treatment with PI3K inhibitor LY294002 alleviated the anti-apoptotic effects of photobiomodulation on $\mathrm{H}_{2} \mathrm{O}_{2}$-treated SCs.

\section{Photobiomodulation alleviates oxidative injury and improves axon regeneration via PI3k/Akt signaling in vitro and in vivo}

To investigate the molecular mechanism by which photobiomodulation protects $\mathrm{SCs}$ against $\mathrm{H}_{2} \mathrm{O}_{2}$-induced apoptosis in vitro, the Nrf2, p-Akt, and Akt protein levels were examined by western blotting analysis. The levels of Akt phosphorylation were slightly higher than in the $\mathrm{H}_{2} \mathrm{O}_{2}$ group, and even higher in photobiomodulation-treated group, which was in accordance with the p-Akt/Akt ratio. The up-regulation was reversed by treatment with LY294002. The Nrf2 protein levels showed a similar trend. These results indicated that the activation of PI3K/Akt signaling contributed to photobiomodulation-treated facial nerve regeneration (Fig. 7A-F).

\section{Discussion}

Many studies have proved that diode laser biological stimulation can promote axonal regeneration and functional recovery (Yazdani et al. 2012; Kouhkheil et al. 2018; Takhtfooladi et al. 2015), which was furthermore confirmed by our study. Although the mechanisms of promotion of nerve regeneration by diode laser biological stimulation still remain unclear, it is believed that the promotion of migration, proliferation, and development of SCs and increased secretion of SCs in a large number of NGF factors that promote axonal extension have a relevant role. Laser treatment can cause the formation of microtubule and microfilament protein in axons chemotactically (Yazdani et al. 2012; Van Breugel and
Bar 2013) and promote vascularization of peripheral nerve regeneration (Masoumipoor et al. 2014).

Recent studies have shown that SCs, the principal glial cells of the PNS, secrete neurotrophic factors that promote the regeneration of the peripheral nerve. Photobiomodulation stimulates the proliferation of SCs in vitro. Many studies have reported that irradiation ranging from 632 to $901 \mathrm{~nm}$ enhances nerve cell differentiation, proliferation, axonal growth and myelination, and improves morphological recovery in experimental sciatic nervous lesions in a dosedependent manner (Pouriran et al. 2016; Sefati et al. 2018; Dias et al. 2019). In our study, the apoptotic rate of SCs in $250 \mathrm{~mW}$ and $500 \mathrm{~mW}$ groups was lower than that in the control group, but the rate of apoptosis in the $1000 \mathrm{~mW}$ group was higher than that of the control group, thus suggesting that photobiomodulation with the parameters of $250 \mathrm{~mW}$ and $500 \mathrm{~W}$ could restrain apoptosis of SCs. In real-time livecell analysis, the proliferation rate of SCs in $250 \mathrm{~mW}$ and $500 \mathrm{~mW}$ groups was higher than that of the control group and $1000 \mathrm{~mW}$ group, indicating that photobiomodulation in $250 \mathrm{~mW}$ and $500 \mathrm{~mW}$ group improved the proliferation of SCs. Immunocytochemistry with anti-S100 $\beta$ and DAPI that served as markers of SCs showed a marked enhancement in purity after the cells were sorted, almost reaching 99\% purity. In addition, western blots also showed a steady increase of NGF in the $500 \mathrm{~mW}$ group, while a much higher level of BDNF was observed in the $250 \mathrm{~mW}$ group.

While the most effective laser application with regard to wavelength, energy density, continuous or pulsed mode, treatment duration time, and the wave is still controversial, the use of laser treatment definitely facilitates nerve regeneration (Kouhkheil et al. 2018; Pol et al. 2016). Our study assessed morphological changes using TEM, showing thicker myelin sheaths with denser alignments in $250 \mathrm{~mW}$ and $500 \mathrm{~mW}$ groups. Many studies have assessed functional recovery, histological and micro-morphological changes, and electrophysiological improvement after the introduction of photobiomodulation, which proved to have beneficial effects on the regeneration of rats' sciatic nerve injury (Kouhkheil et al. 2018; Pol et al. 2016; Mashhoudi Barez et al. 2017). Wang et al. (2014) have reported that an 808-nm laser treatment with energy density $\left(3 \mathrm{~J} / \mathrm{cm}^{2}\right.$ and $\left.8 \mathrm{~J} / \mathrm{cm}^{2}\right)$ is capable of enhancing sciatic nerve regeneration after a crush injury. Buchaim et al. (2015) have reported that laser treatment (wavelength of $830 \mathrm{~nm}, 30 \mathrm{~mW}$ optical power output of potency, and energy density of $6 \mathrm{~J} / \mathrm{cm}^{2}$ ) has satisfactory results on facial nerve regeneration. The irradiation parameters they described were different from ours, where we showed that photobiomodulation of $980 \mathrm{~nm}$ performed on day 1 after surgery and during the postoperative period (three times weekly for a total of 5 weeks) at output power $(250 \mathrm{~mW}, 500 \mathrm{~mW}$, and $1000 \mathrm{~mW})$ accelerated functional 


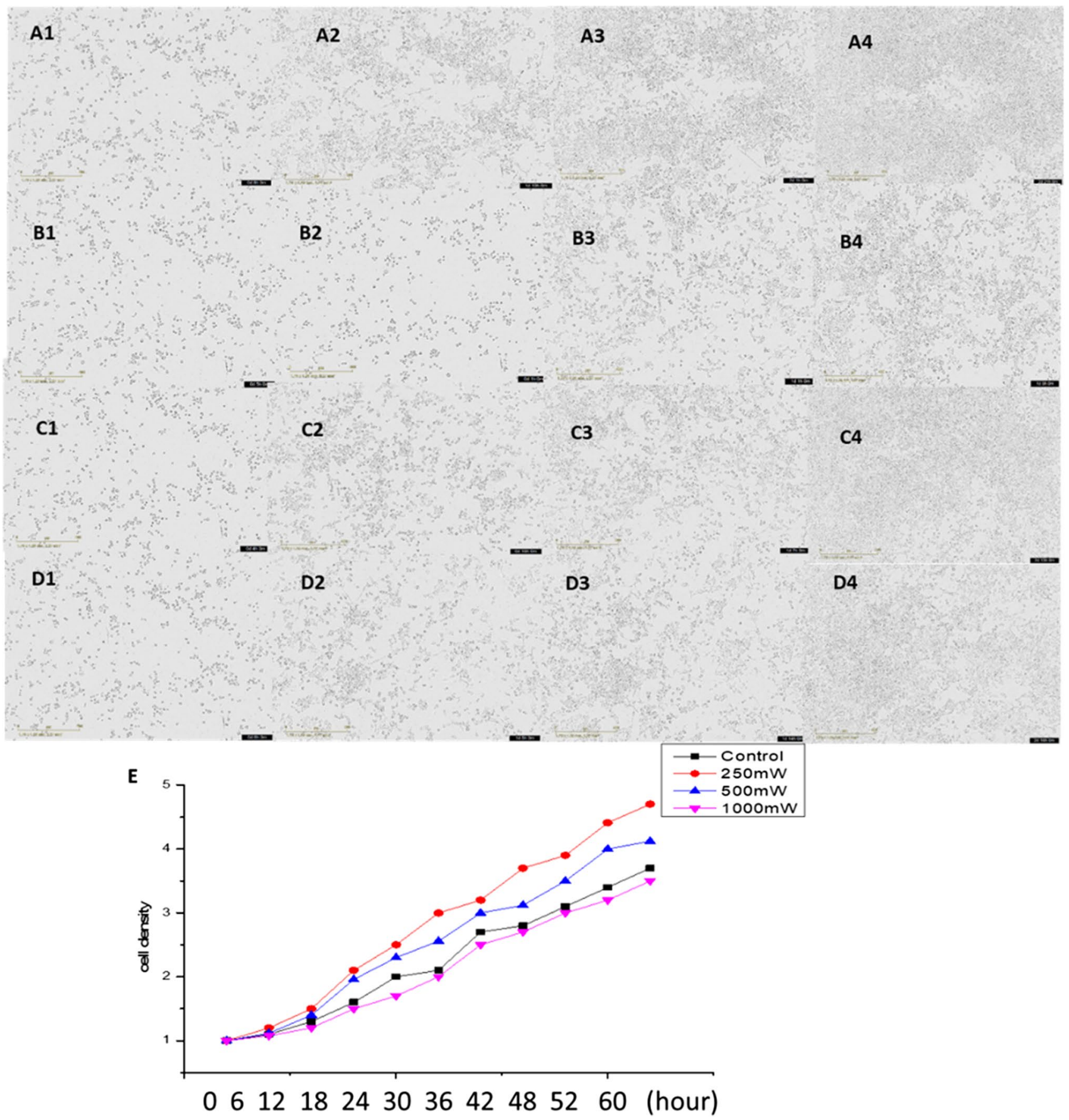

Fig. 5 SCs proliferation by IncuCyte. The real-time live SCs evolution of an IncuCyte assay. Images taken after (a) 0, (b) 8, (c) 16, (d) 24, and (e) $46 \mathrm{~h}$ after the scratch was performed (A, control; B, $250 \mathrm{~mW}$; C, $500 \mathrm{~mW}$; D, $1000 \mathrm{~mW}$ ). The scale bar corresponds to

recovery and enhanced facial nerve regeneration in crush injury.

Several lines of evidence have implicated the involvement of PI3K/Akt signaling in modifying the survival, growth, splitting, proliferation, and apoptosis of SCs (Huang et al. 2017; Sang et al. 2018). Additionally, PI3K/Akt signaling
$300 \mu \mathrm{m} . \mathrm{F}$, comparison of the average experimental cell density $\mathrm{C}(\mathrm{t})$ (crosses) and the logistic growth curve using our estimates of $\mathrm{K}$ and $\lambda$ (solid)

pathway has a critical survival factor role in repairing and regeneration processes after nerve injury (Sang et al. 2018). Activation of PI3K/Akt signaling blocks the mitochondrial apoptotic pathway, while inhibition of PI3K/ Akt signaling activates the apoptotic pathway (Huang et al. 2017; Mashhoudi Barez et al. 2017). In this study, the 


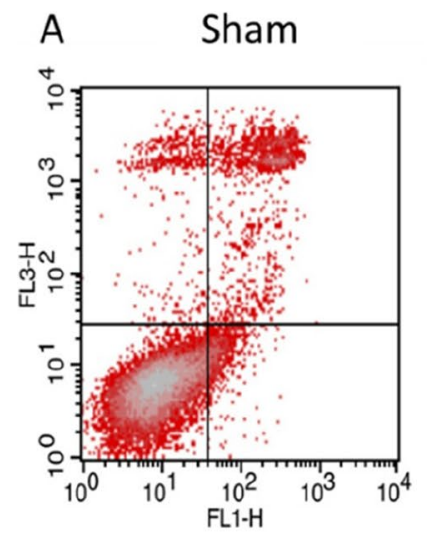

E

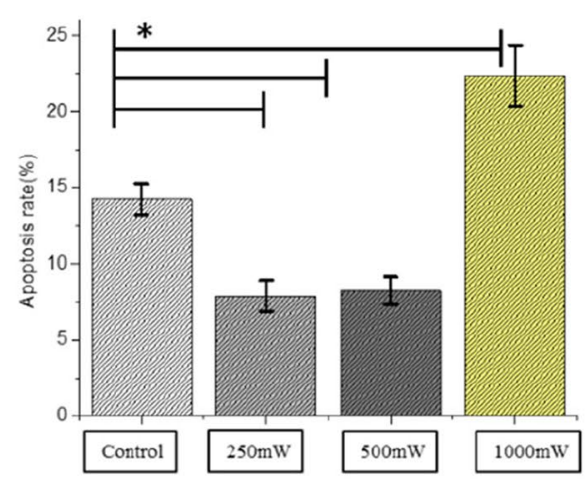

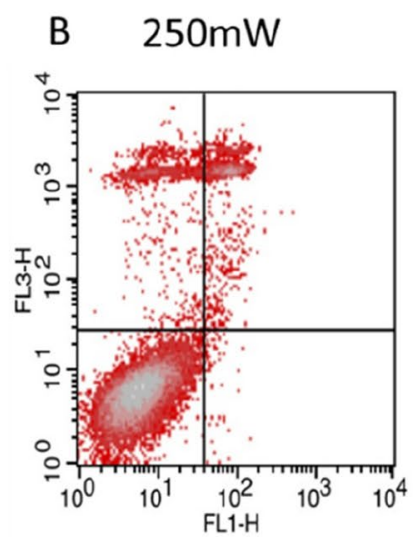

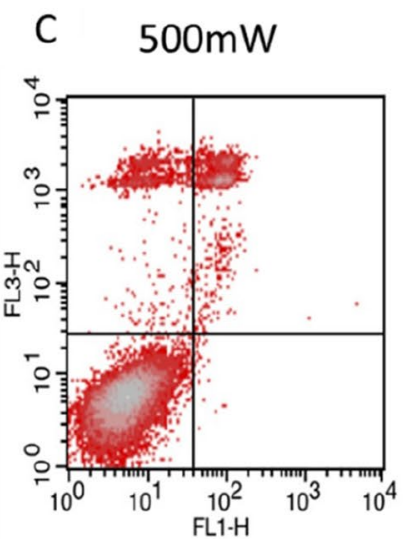

$\mathrm{F}$

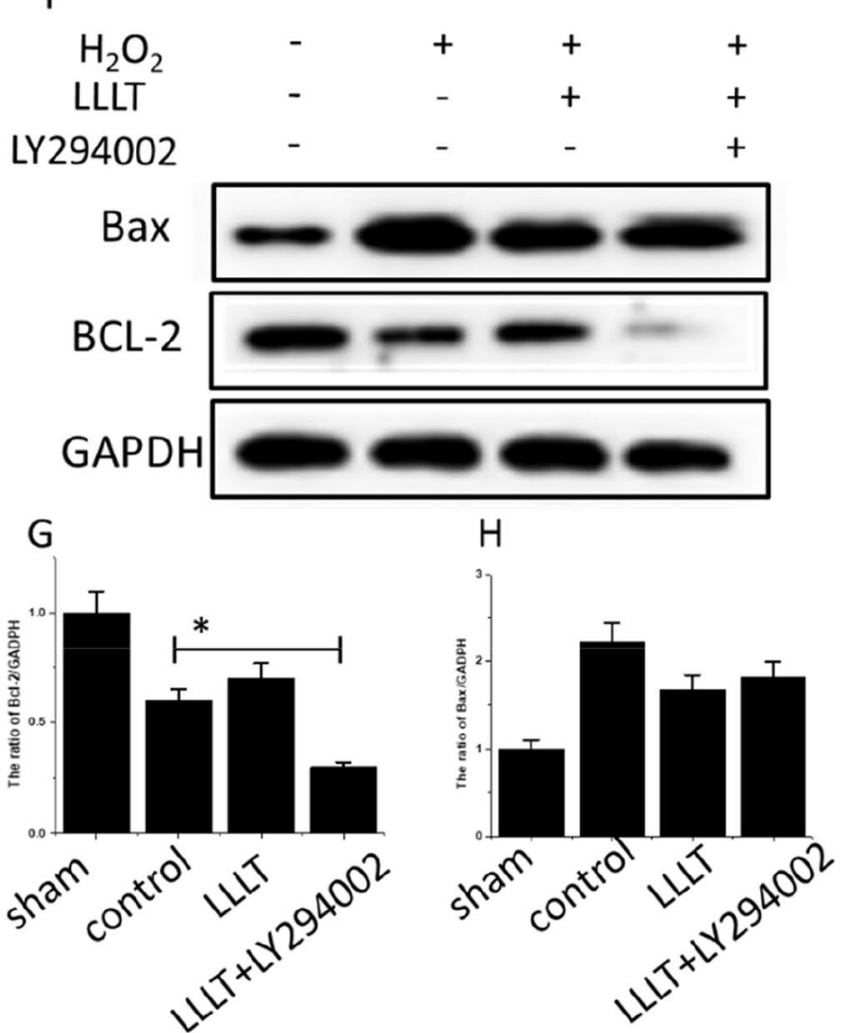

Fig. 6 Photobiomodulation inhibits SCs apoptosis in vitro. A-E, apoptosis of SCs treated with photobiomodulation was analyzed by Annexin V and PI staining. The apoptotic rate in $250 \mathrm{~mW}$ and $500 \mathrm{~mW}$ groups was significantly decreased, while in $1000 \mathrm{~mW}$

photobiomodulation in $250 \mathrm{~mW}$ improved phosphorylation of Akt through PI3K activation and prevented apoptosis of SCs induced by inhibiting Akt phosphorylation. Following Akt phosphorylation, the activation of the PI3K/Akt signaling pathway was mediated by $\mathrm{Bcl}-2$ phosphorylation, and subsequent inhibition of Bcl-2 and BAD phosphorylation (Andraus et al. 2017; Chang et al. 2017). Phosphorylated BAD then binds to 14-3-3 protein, releasing Bcl-xL into the cytoplasm (Dong et al. 2019; Andraus et al. 2017; Chang et al. 2017). The release of Bcl-xL, in turn, unblocks the groups it was significantly increased after treatment with photobiomodulation. Data were presented as means $\pm \mathrm{SD}$ values. $* \mathrm{P}<0.05 \mathbf{F}$, the protein levels of Bax and $\mathrm{Bcl}-2$ were detected by western blotting; G-H, quantification analysis of Bax and Bcl-2 expression. $* \mathrm{P}<0.05$

translocation of Bax protein into the mitochondria, resulting in disruption of mitochondrial membrane potential (MMP).

$\mathrm{Nrf} 2$ is a vital regulator of oxidative damage, neural protective functioning, and inflammation modulation that are involved in the traumatic brain injury models (Dong et al. 2019; Wu et al. 2016). In this study, the protein levels of Nrf2 were slightly higher in the $\mathrm{H}_{2} \mathrm{O}_{2}$ group, and were further higher in photobiomodulation-treated group, while treatment with LY294002 reversed these effects. Oxidative stress activity decreased anti-apoptotic protein Bcl-2 


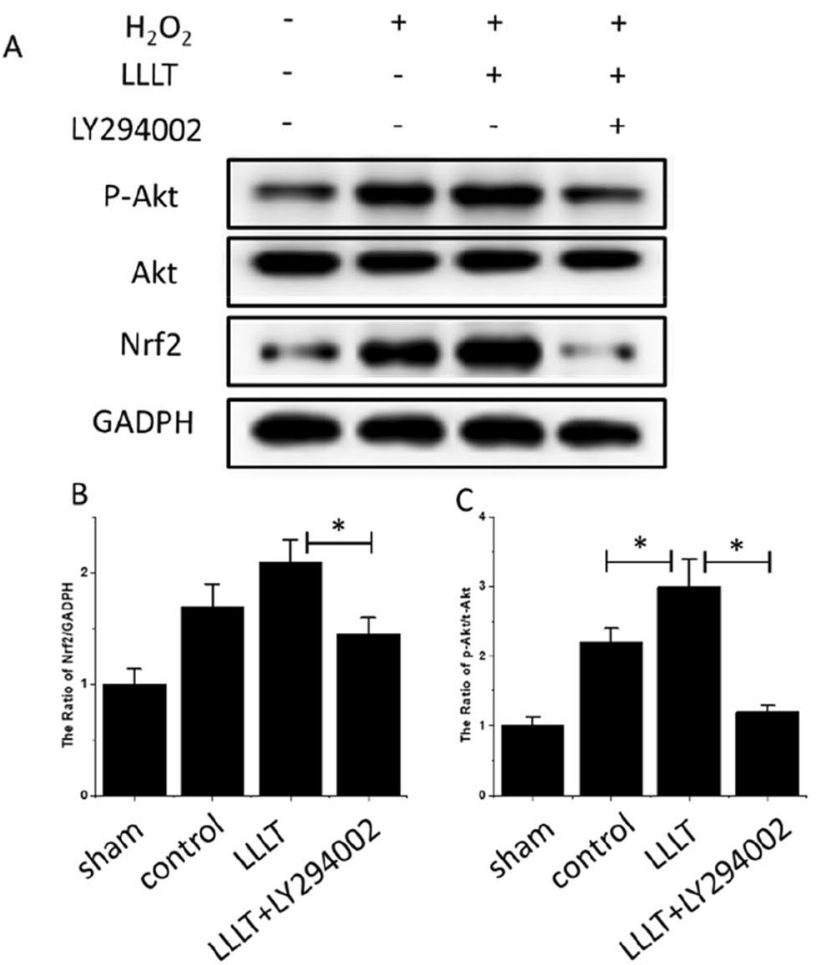

Fig. 7 Photobiomodulation reduces SC apoptosis and improves facial nerve regeneration through $\mathrm{PI} 3 \mathrm{~K} / \mathrm{AKT}$ signaling pathway. $\mathbf{A}-\mathbf{C}$, the protein expression of p-Akt, Akt, and Nrf2 in SCs were detected by western blotting. D-F, the protein expressions of p-Akt, Akt, and

and increased the expression of pro-apoptotic protein Bax, severely influencing cell survival and inducing cell apoptosis (Huang et al. 2017; Dong et al. 2019; Sang et al. 2018). In our study, the protein levels of Bcl-2 were up-regulated, but the protein levels of Bax were down-regulated after oxidative damage treated with photobiomodulation, while this effect was partially reversed by a combination of photobiomodulation and LY294002. This result indicated that oxidative apoptosis after peripheral nerve injury was probably regulated by PI3K/Akt signaling. In our study, the expression levels of phosphorylated p-Akt/Akt and Nrf2 and the dimerization of Bax/Bcl-2 level were assessed in regular photobiomodulation used to treat crushed facial nerve. In addition, the effect of photobiomodulation in $250 \mathrm{~mW}$ combined with PI3K/Akt pathway inhibitor (LY294002) was examined in SCs in vitro, which indicated that apoptosis of SCs occurs through down-regulation of PI3K/Akt signaling in vitro.

To test whether photobiomodulation treatment inhibits crushed-induced oxidative stress in the facial nerve via PI3K/Akt, the expression of oxidative stress-related proteins Nrf2, P-Akt, and Akt was detected by western blotting. The level of Nrf2 was higher in the injury group and lower in the injury-added-with-LY29400 group. The ratio

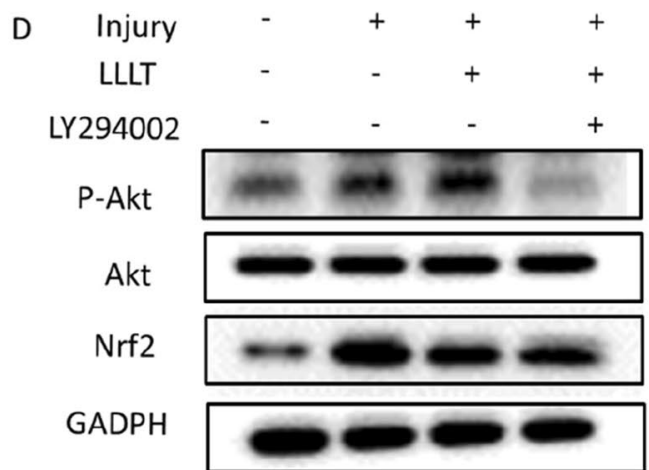

$\mathrm{E}$

$\mathrm{F}$
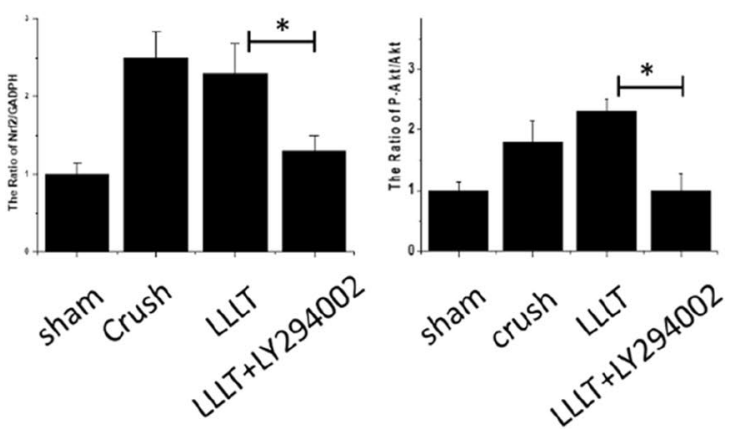

Nrf2 in the facial nerve were detected by western blotting. In vivo and In vitro western blotting results show photobiomodulation improves the facial nerve regeneration through the PI3K/AKT signaling pathway. $* \mathrm{P}<0.05$

of P-Akt/Akt was higher in the injury group and lower in the injury-added-with-LY29400 group. The levels of Akt phosphorylation were slightly increased after PNI, and these levels were even higher after PNI rats received photobiomodulation treatment, which was also confirmed by the $p$ -Akt/Akt ratio. These results suggest that photobiomodulation in $250 \mathrm{~mW}$ induces mitochondrial-dependent apoptosis by down-regulation of PI3K/Akt signaling in the rat facial nerve in vivo. Furthermore, PI3K-Akt activation mainly contributed to neuroprotection through post-conditioning treatment (Dong et al. 2019; Sang et al. 2018).

This paper has some limitations. In this study, crush injury was used as an in vivo injury model according to the previous literature. Other studies used the feedbackcontrolled electronic squeezer method, which is considered to be more objective in recording the degree of damage. Furthermore, hydrogen peroxide-damaged SCs were used as in vitro injury models according to the previous literature. During the process of peripheral nerve regeneration and repair, the early stage (4-week time point) data remained unstable, while the overall trend of 12 treatment at week 8 showed the best treatment effect in the $250 \mathrm{~mW}$ group, which was similar to the previous study ( $\mathrm{Lv}$ et al. 2017). We only checked the energy density of $16.71 \mathrm{~J} / \mathrm{cm}^{2}$ on a facial nerve 
in crush injury. To investigate the molecular mechanism, we only focused on the effective results of the pathway of $\mathrm{PI} 3 \mathrm{~K} / \mathrm{AKT}$ in the facial crush nerve and did not address the negative effects on the normal, natural nerve. We used the photobiomodulation on the crushed facial nerve from the day after surgery till the postoperative period 3 times per week for 5 consecutive weeks; however, the observation and evaluation time lasted 12 weeks.

\section{Conclusion}

Based on the results of the present study, the application of a laser source at a $980-\mathrm{nm}$ wavelength and at doses of $250 \mathrm{~mW}$ and $500 \mathrm{~mW}$ to an injured rat facial nerve immediately after crush injury had a beneficial effect on facial nerve regeneration, including better functional recovery and morphological changes. In addition, the neuroprotective function of photobiomodulation was associated with excessive suppression of oxidative stress-induced SCs apoptosis via activation of the PI3K/Akt signaling pathway. These results indicated that photobiomodulation might be regarded as a potential therapeutic agent for peripheral nerve reconstruction after injury.

Author contributions Bohan Li and Xiao Wang designed the research. Bohan Li performed the main experiments, analyzed the data, and wrote the manuscript.

Funding Key Clinical Projects of Peking University Third Hospital, No. BYSYZD2019009.

\section{Declarations}

Conflict of interest The authors declare no competing interests.

Open Access This article is licensed under a Creative Commons Attribution 4.0 International License, which permits use, sharing, adaptation, distribution and reproduction in any medium or format, as long as you give appropriate credit to the original author(s) and the source, provide a link to the Creative Commons licence, and indicate if changes were made. The images or other third party material in this article are included in the article's Creative Commons licence, unless indicated otherwise in a credit line to the material. If material is not included in the article's Creative Commons licence and your intended use is not permitted by statutory regulation or exceeds the permitted use, you will need to obtain permission directly from the copyright holder. To view a copy of this licence, visit http://creativecommons.org/licenses/by/4.0/.

\section{References}

Andraus RAC, Maia LP, de Souza Lino AD, Fernandes KBP, de Matos Gomes MV, de Jesus Guirro RR, Barbieri CH (2017) LLLT actives MMP-2 and increases muscle mechanical resistance after nerve sciatic rat regeneration. Lasers Med Sci 32:771-778
Buchaim RL, Andreo JC, Barraviera B, Ferreira Junior RS, Buchaim DV, Rosa Junior GM, de Oliveira AL, de Castro Rodrigues A (2015) Effect of low-level laser therapy (LLLT) on peripheral nerve regeneration using fibrin glue derived from snake venom. Injury 46:655-660

Cakir M, Colak A, Calikoglu C, Taspinar N, Sagsoz ME, Kadioglu HH, Hacimuftuoglu A, Seven S (2016) Once the Light Touch to the Brain: Cytotoxic Effects of Low-Dose Gamma-Ray Laser Light, and Visible Light on Rat Neuronal Cell Culture. Eurasian J Med 48:76-83

Chang YM, Chang HH, Tsai CC, Lin HJ, Ho TJ, Ye CX, Chiu PL, Chen YS, Chen RJ, Huang CY, Lin CC (2017) Alpinia oxyphylla Miq. fruit extract activates IGFR-PI3K/Akt signaling to induce Schwann cell proliferation and sciatic nerve regeneration. BMC Complement Altern Med 17:184

Chao X, Xu L, Li J, Han Y, Li X, Mao Y, Shang H, Fan Z, Wang $H$ (2016) Facilitation of facial nerve regeneration using chitosan-beta-glycerophosphate-nerve growth factor hydrogel. Acta oto-laryngologica 136:585-591

Dias FJ, Fazan VPS, Cury DP, de Almeida SRY, Borie E, Fuentes R, Coutinho-Netto J, Watanabe IS (2019) Growth factors expression and ultrastructural morphology after application of low-level laser and natural latex protein on a sciatic nerve crush-type injury. PLoS One 14

Dong L, Li R, Li D, Wang B, Lu Y, Li P, Yu F, Jin Y, Ni X, Wu Y, Yang S, Lv G, Li X, Xiao J, Wang J (2019) FGF10 Enhances Peripheral Nerve Regeneration via the Preactivation of the PI3K/AktSignaling-Mediated Antioxidant Response. Front Pharmacol 10:1224

Hou B, Ye Z, Ji W, Cai M, Ling C, Chen C, Guo Y (2018) Comparison of the Effects of BMSC-derived Schwann Cells and Autologous SchwannCells on Remyelination Using a Rat Sciatic Nerve Defect Model. Int J Biol Sci 14:1910-1922

Huang HT, Sun ZG, Liu HW, Ma JT, Hu M (2017) ERK/MAPK and $\mathrm{PI} 3 \mathrm{~K} / \mathrm{AKT}$ signal channels simultaneously activated in nerve cell and axon after facial nerve injury. Saudi J Biol Sci 24:1853-1858

Kouhkheil R, Fridoni M, Piryaei A, Taheri S, Chirani AS, Anarkooli IJ, Nejatbakhsh R, Shafikhani S, Schuger LA, Reddy VB, Ghoreishi SK, Jalalifirouzkouhi R, Chien S, Bayat M (2018) The effect of combined pulsed wave low-level laser therapy and mesenchymal stem cell-conditioned medium on the healing of an infected wound with methicillin-resistant Staphylococcal aureus in diabetic rats. J Cell Biochem 119:5788-5797

Lee SH, Jin WP, Seo NR, Pang KM, Kim B, Kim SM, Lee JH (2017) Recombinant human fibroblast growth factor-2 promotes nerveregeneration and functional recovery after mental nerve crush injury. Neural Regen Res 12:629-636

Li BH, Kim SM, Yoo SB, Kim MJ, Jahng JW, Lee JH (2012) Recombinant human nerve growth factor (rhNGF-beta) gene transfer promotesregeneration of crush-injured mental nerve in rats. Oral Surg Oral Med Oral Pathol Oral Radiol 113:e26-34

Lv MR, Li B, Wang MG, Meng FG, Yu JJ, Guo F, Li Y (2017) Activation of the PI3K-Akt pathway promotes neuroprotection of the delta-opioid receptor agonist against cerebral ischemia-reperfusion injury in rat models. Biomed Pharmacother 93:230-237

Mao Q, Nguyen PD, Shanti RM, Shi S, Shakoori P, Zhang Q, Le AD (2018) Gingiva-Derived Mesenchymal Stem Cell-Extracellular Vesicles ActivateSchwann Cell Repair Phenotype and Promote Nerve Regeneration, Tissue Eng PartA. https://doi.org/10.1089/ ten.TEA.2018.017

Mashhoudi Barez M, Tajziehchi M, Heidari MH, Bushehri A, Moayer F, Mansouri N, Safavi Naini N, Movafagh A (2017) Stimulation Effect of Low Level Laser Therapy on Sciatic Nerve Regeneration in Rat. J Lasers Med Sci 8:S32-S37

Masoumipoor M, Jameie SB, Janzadeh A, Nasirinezhad F, Soleimani M, Kerdary M (2014) Effects of 660- and 980-nm low-level laser 
therapy on neuropathic pain relief following chronic constriction injury in rat sciatic nerve. Lasers Med Sci 29:1593-1598

Pol R, Gallesio G, Riso M, Ruggiero T, Scarano A, Mortellaro C, Mozzati M (2016) Effects of Superpulsed, Low-Level Laser Therapy on Neurosensory Recovery of the Inferior Alveolar Nerve. J Craniofac Surg 27:1215-1219

Pouriran R, Piryaei A, Mostafavinia A, Zandpazandi S, Hendudari F, Amini A, Bayat M (2016) The Effect of Combined Pulsed Wave Low-Level Laser Therapy and Human Bone Marrow Mesenchymal Stem Cell-Conditioned Medium on Open Skin Wound Healing in Diabetic Rats. Photomed Laser Surg 34:345-354

Quintes S, Brinkmann BG (2017) Transcriptional inhibition inSchwann cell development and nerve regeneration. Neural Regen Res 12:1241-1246

Rimington RP, Capel AJ, Player DJ, Bibb RJ, Christie SDR, Lewis MP (2018) Feasibility and Biocompatibility of 3D-Printed Photopolymerized and Laser Sintered Polymers for Neuronal Myogenic, and Hepatic Cell Types. Macromol Biosci 18:e1800113

Sang Q, Sun D, Chen Z, Zhao W (2018) NGF and PI3K/Akt signaling participate in the ventral motor neuronal protection of curcumin in sciatic nerve injury rat models. Biomed Pharmacother 103:1146-1153

Sefati N, Abbaszadeh HA, Fadaei Fathabady F, Abdollahifar MA, Khoramgah MS, Darabi S, Amini A, Tahmasebinia F, Norouzian M (2018) The Combined Effects of Mesenchymal Stem Cell Conditioned Media and Low-Level Laser on Stereological and Biomechanical Parameter in Hypothyroidism Rat Model. J Lasers Med Sci 9:243-248

Seo N, Lee SH, Ju KW, Woo J, Kim B, Kim S, Jahng JW, Lee JH (2018) Low-frequency pulsed electromagnetic field pretreated bonemarrow-derived mesenchymal stem cells promote the regeneration of crush-injuredrat mental nerve. Neural Regen Res $13: 145-153$

Shibeeb O, Wood JP, Casson RJ, Chidlow G (2014) Effects of aconventional photocoagulator and a 3 -ns pulse laser on preconditioningresponses and retinal ganglion cell survival after optic nerve crush. Exp Eye Res 127:77-90

Takhtfooladi MA, Jahanbakhsh F, Takhtfooladi HA, Yousefi K, Allahverdi A (2015) Effect of low-level laser therapy $(685 \mathrm{~nm}, 3 \mathrm{~J} /$ $\mathrm{cm}(2)$ ) on functional recovery of the sciatic nerve in rats following crushing lesion. Lasers Med Sci 30:1047-1052

Van Breugel HH, Bar PR (1993) He-Ne laser irradiation affects proliferation of cultured rat Schwann cells in a dose-dependent manner. J Neurocytol 22:185-190

Wang CZ, Chen YJ, Wang YH, Yeh ML, Huang MH, Ho ML, Liang JI, Chen CH (2014) Low-level laser irradiation improves functional recovery and nerve regeneration in sciatic nerve crush rat injury model. PLoS One 9:e103348

Wang Y, Shan Q, Pan J, Yi S (2018) Actin Cytoskeleton AffectsSchwann Cell Migration and Peripheral Nerve Regeneration. Front Physiol 9:23

Wu W, Liu Y, Wang Y (2016) Sam68 promotes Schwann cell proliferation by enhancing the PI3K/Akt pathway and acts on regeneration after sciatic nerve crush. Biochem Biophys Res Commun 473:1045-1051

Yasui G, Yamamoto Y, Shichinohe R, Funayama E, Oyama A, Hayashi T, Furukawa H (2016) Neuregulin-1 released by biodegradable gelatinhydrogels can accelerate facial nerve regeneration and functional recovery oftraumatic facial nerve palsy. J Plast Reconstr Aesthet Surg 69:328-334

Yazdani SO, Golestaneh AF, Shafiee A, Hafizi M, Omrani HA, Soleimani M (2012) Effects of low level laser therapy on proliferation and neurotrophic factor gene expression of human schwann cells in vitro. J Photochem Photobiol B 107:9-13

Publisher's note Springer Nature remains neutral with regard to jurisdictional claims in published maps and institutional affiliations. 